\title{
Pelvic Abscess Formation Secondary to the Use of Commercial Hemostatic Topical Agent in an Immune Compromised Patient?
}

\author{
Mónica Monzón-Vargas, Yuliana Gómez-Meraz and Rodrigo Ayala-Yáñez* \\ ABC Medical Center, Mexico
}

Submission: May 26, 2017 ; Published: June 19, 2017

*Corresponding author: Rodrigo Ayala-Yáñez, ABC Medical Center, Av. Carlos Graéf Fernández 154-339, Tlaxala Santa Fe, Cuajimalpa, México, Tel: 525516647208; Email: rayalaabc@gmail.com

\begin{abstract}
Various hemostatic agents are currently available for routine laparoscopic procedures, avoiding thermal lesions due to energy devices and the complexity of intracorporeal sutures, however, evidence of complications in immune compromised patients is still lacking. We present the case of a severely immune compromised gynecological patient who underwent a routine laparoscopic cystectomy, where a local hemostatic agent was employed; further complications arose, a second diagnostic laparoscopy revealed a pelvic abscess with severe adhesion formation. All under a complicated clinical setting due to an impaired immune response, whether this abscess was caused due to the hemostatic agent or other patient's conditions remains to be determined, still, various clinical factors and patient's response need to be taken into account as the cause of the abscess formation.
\end{abstract}

Keywords: Hemostatic agent; Pelvic abscess; Laparoscopy; Immuno compromised patient; Cystectomy

\section{Introduction}

Bleeding control is one of the most important goals during any surgery. Alternative to the standard suture materials and energy devices, a great variety of topical hemostatic agents and tissue adhesives are currently available in order to improve outcomes such as reduced blood loss, need for blood transfusion, shorter surgery times and risk for re intervention $[1,2]$.

At present, precise indications should be followed since complications may arise as we present in the following case report. The aim of this article is to review the medical and scientific information regarding hemostatic agents.

We present a rare case in an immune compromised patient who underwent a cystectomy, laparoscopic surgery in which the topical hemostatic agent "Surgiflo®" was used to stop oozing .Patient's outcome was complicated with a pelvic abscess and severe adhesion process that required an open surgical intervention.

\section{Case Report}

We present the case of a 26-year- old woman, nulligravida with relevant clinical history of systemic lupus erythematosus (SLE), chronic anemia, hypertension, diabetes and end stage renal disease, treated with renal transplant complicated with chronic allograft rejection that conditioned her to require hemodialysis 3 times per week. Current medications include: Tacrolimus, Azathioprine, and Prednisone.

Clinical findings on admission were: acute pelvic pain accompanied with profuse trans vaginal bleeding. Endovaginal ultrasonogram revealed the presence of a $6 \mathrm{~cm}$ cystadenoma in the left ovary and free fluid in the pelvic cavity. All her laboratory tests were normal no sign of infection was recorded previous to the surgical procedure.

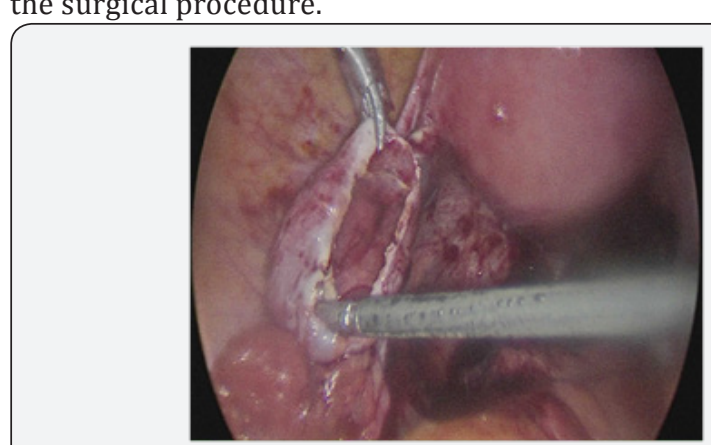

Figure 1: First intervention, ovary cyst treated with a laparoscopic cystectomy with capsule resection. 


\section{Journal of Gynecology and Women's Health}

Laparoscopic findings were compatible with endometriosis, adhesions in the cul de sac were identified and surgery was performed with Thunder beat ${ }^{\circledR}$ energy device. Aspiration and capsule resection completed the procedure (Figure 1).

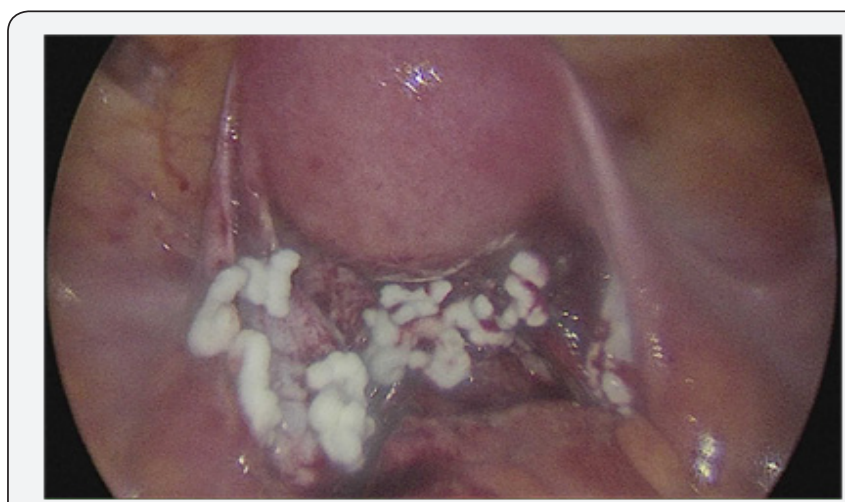

Figure 2: Excessive application of hemostatic agent on the posterior cul de sac as well as lower uterine segment. This would be the exact site were adhesions developed as well as the pelvic abscess

Despite initial hemostasis, posterior cul de sac (where the adhesiolys is took place) presented oozing and the topical hemostatic agent Surgiflo® was applied in order to prevent an hematoma formation, achieving adequate hemostasis (Figure 2). Patient was discharged 2 days later, developing urinary tract infection positive for Ureaplasma urealyticum, that was treated with broad spectrum antibiotics.

Fourteen days later Bacteroides fragilis was inoculated in a blood sample and was treated with vancomycin and ertapenem. Patient's response wasn't satisfactory despite all the precautions and multidisciplinary approaches. She continued to have intermittent fever and diarrhea (although all her coprological cultures were negative).

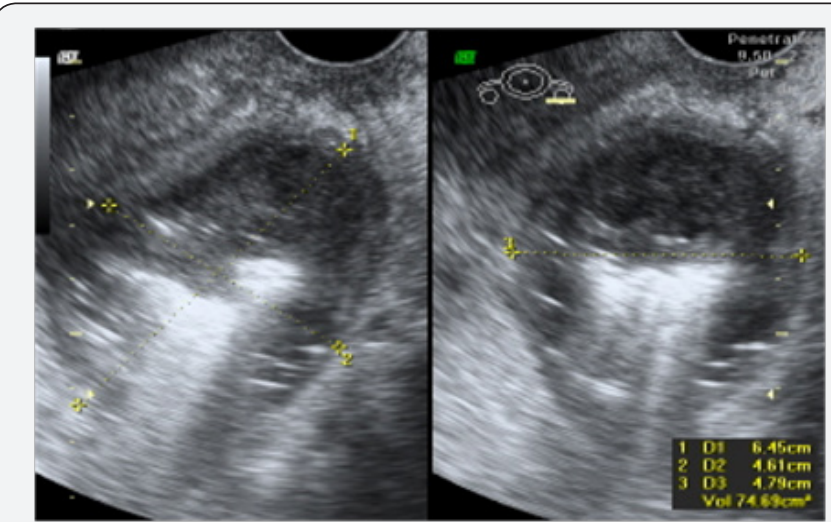

Figure 3: Ultrasound image revealing the presence of a pelvic abscess

After four weeks, the patient was readmitted due the presence of persistent fever and pelvic pain. Laboratory tests reported slightly increased leucocytes $(9.7 \times 103 \mu \mathrm{L})$, low hemoglobin of $(7.3 \mathrm{~g} / \mathrm{dL}), 3$ bands, procalciton in of $0.6 \mathrm{ng} / \mathrm{m}$ Land an elevated Creactive protein (CPR, $13.97 \mathrm{mg} / \mathrm{dL}$ ). Blood, urine, stool and cervicovaginal cultures were negative. Ultrasound reported a
$7 \mathrm{~cm}$, diameter collection with heterogeneous characteristics with fluid contents located in the posterior cul de sac, compatible with remnants of an hemostatic agent (Figure 3).

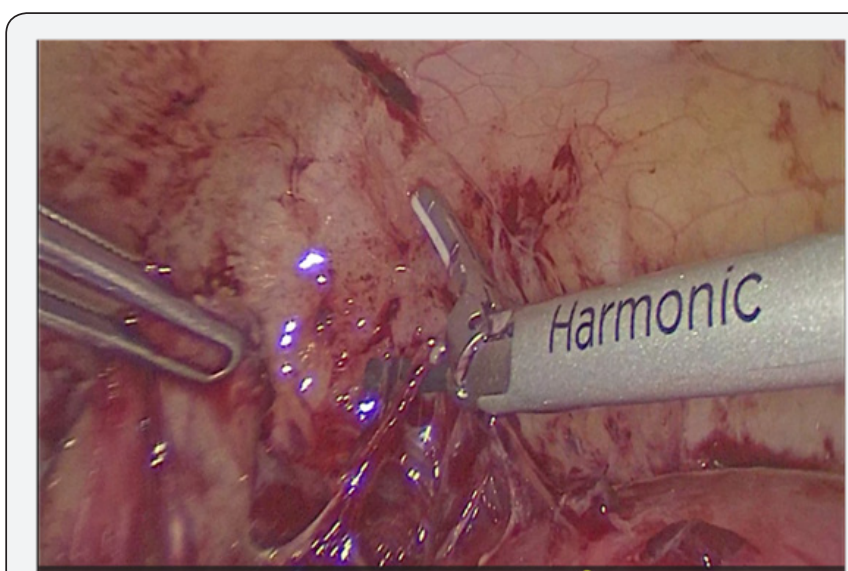

Figure 4: Severe adhesion process developed over the entire posterior cul de sac, uterus and partial peritoneal walls.

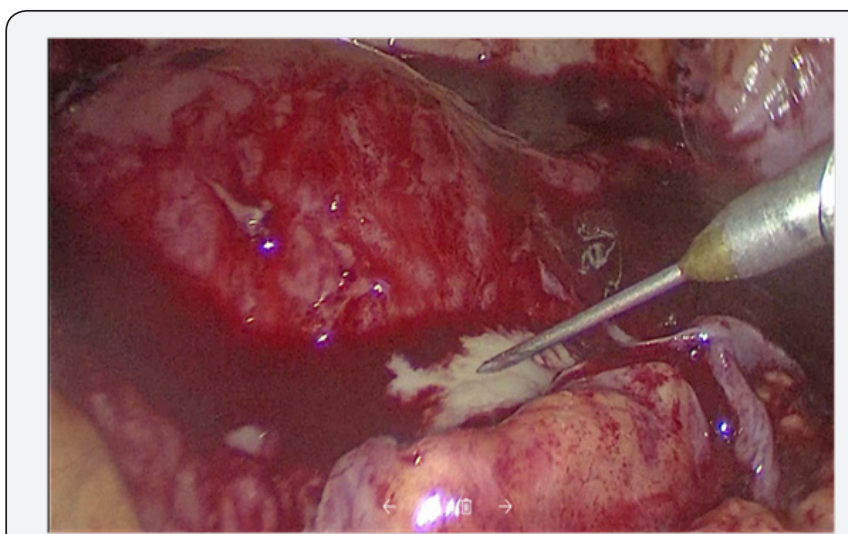

Figure 5: Second intervention, with initial laparoscopy diagnosis, this procedure revealed the severe adhesion process, as well as the abscess where a purulent material was drained.

Since the etiology of the fever wasn't determined, a second diagnostic laparoscopy was performed. During this procedure, multiple adhesions that distorted normal anatomy were identified, an abscess of $2 \mathrm{~cm}$ in diameter was found in the posterior cul de sac, firmly attached to the left ovary and rectum. Due to the severe adhesion process, laparotomy conversion was opted. In the open procedure, adhesion removal and exhaustive pelvic cavity lavage were performed, the abscess drained $15 \mathrm{ml}$ of purulent material with no characteristic smell, samples were taken for microbiologic cultures (Figures 4 \& 5), (no pathogen was isolated). A sponge like material was found and taken out of the posterior cul de sac, compatible with the common degradation process of the hemostatic agent. Parenteral antimicrobial medication was initiated with adequate response, discharging the patient 1 week later. No further complications were reported.

\section{Discussion}

This clinical case presents a severely immunocompromised woman who was attended for a relatively common gynecological 
condition and subsequently complicated with a pelvic abscess and adhesion process.

The possible associations of hemostatic agents with infective complications are listed as follows:

1. Histologic changes with granulomatous reaction secondary to foreign material [3].

2. Delayed time of absorption of some hemostatic agents [4-6].

3. Biological material agents are prompt for colonization serving as culture media $[7,8]$.

4. Incorrect amounts and disposal of hemostatic agents may lead to adhesion formation $[7,9]$.

5. Some agents promote a diminished $\mathrm{pH}$ on nearby environments, disrupting local innate defense immune mechanisms such as protease activity $[1,10]$. On the other hand, oxidized regenerated cellulose hemostatics are considered bactericidal, due to their acidification of the media [2].

Previous studies performed on immunocompetent patients identified risk factors for abscess formation such as untreated pelvic inflammatory disease, endometriosis, previous laparotomy and post-operative hematomas [11-13]. Hemostatic agents have been suggested as an added risk factor for infection in these clinical settings; however we currently lack quality evidence to support this statement. Additionally, studies that address this question in immunocompromised subjects are needed.

Clinical benefits of the hemostatic agents, supported by existing studies are:

a. Preventing thermal damage on vascular and nerve structures (as when electrosurgery is employed).

b. Achieving early and adequate hemostatic control in friable tissues.

c. Better outcomes in patients with hemorrhagic diathesis [14-16].

Risk of infection secondary to fluid hemostatics such as Floseal ${ }^{\circledR}$ or Surgiflo@ may be minimized by removing the excess of this topical hemostatic agent from the wound after hemostasis is achieved, since excessive amounts of slowly degrading products can serve as a site for infection development $[17,18]$.

In this, case the underlying clinical conditions placed the patient at higher risk for any type of infection in comparison with the rest of the population, hence, secondary abscess formation couldn't be stablished with certainty.

Finally, current guidelines on late abdominal sepsis state that a possible mechanism explaining the presence of anaerobic pathogens similar to the one presented, is bacterial translocation which presumably caused bacteremia with B. fragilis. No pathogen was inoculated in the second procedure probably due to the previous administration of broad spectrum antibiotics.

\section{Conclusion}

Because of the insufficient evidence available, the authors' recommendation is to avoid excessive use of this type of hemostatic in immunocompromised patients.

If strictly necessary, and the patient's condition warrants it, we suggest choosing a rapid resorption hemostat such as Microporous Polysaccharide Spheres like Arista ${ }^{\circledR}$ as first choice, this one shows complete resorption within 48 hours vs gelatin matrix agents that can take 6 to 8 weeks to disintegrate. Surplus hemostatic agents should be removed after achieving the desired effect.

\section{Conflict of Interest}

Authors have no disclosures and no conflict of interest.

\section{References}

1. De la Torre A, Bachman S, Wheeler A, Bartow K, Scott J (2007) Hemostasis and hemostatic agents in minimally invasive surgery. Sugery 142(4 Suppl): S39-S45.

2. Peralta E (2017) Overview of topical hemostatic agents and tissues adhesives.

3. Shashoua AR, Gill D, Barajas R, Dini M, August C, et al. (2009) Caseating granulomata caused my hemostatic agent posing as metastatic leiomyosarcoma. J Soc Laparoscop Surg 13(2): 226-228.

4. Watrowski R, Jager C, Forster J (2017) Improvement of Perioperative Outcomes in Major Gynecological and Gynecologic-Oncological Surgery with Hemostatic Gelatin-Thrombin Matrix. In Vivo 31(2): 251- 258.

5. Duenas-Garcia O, Goldberg J (2008) Topical Hemostatic Agents in Gynecologic Surgery. Obstet Gynecol Surv 63(6): 389-394.

6. Wysham W, Roque D, Soper J (2014) Use of topical hemostatic agents in gynecologic surgery. Obstet Gynecol Surv 69(9): 557-563.

7. Hobday D, Milam M, Milam R, Euscher E, Brown J (2009) Postoperative Small Bowel Obstruction Associated with use of Hemostatic Agents. J Minim Invasive Gynecol 16(2): 224-226.

8. Fagotti A, Costantini B, Fanfani F, Vizzielli G, Rossitto C, et al. (2010) Risk of postoperative pelvic abscess in major gynecology oncology surgery: one- year single- institution experience. Ann Surg Oncol 17(9): 2452-2458.

9. Cağlar M, Yavuzcan A, Ylldız E, Yılmaz B, Dilbaz S, et al. (2014) Increased adhesion formation after gelatin- thrombin matrix application in a rat model. Arch Gynecol Obstet 290(3): 501-506.

10. Camp MA (2014) Hemostatic Agents: A guide to safe practice for perioperative nurses. AORN Journal 100(2): 131-147.

11. Obermair H, Janda M, Obermair A (2016) Real- world surgical outcomes of gelatin- hemostatic matrix in women requiring a hysterectomy: a matched case- control study. Acta Obstet Gynecol Scand 95(9): 1008-1014.

12. Anderson CK, Medlin E, Ferris AF, Sheeder J, Davidson S, et al. (2014) Association between gelatin thrombin matrix use and abscesses in women undergoing pelvic surgery. Obstet Gynecol 124(3): 589-595.

13. Zand B, Frumovitz M, Jofre MF, Nick AM, Dos Reis R, et al. 2012. Risk factors for prolonged hospitalization after gynecologic laparoscopic surgery. Gynecol Oncol 126(3): 428-431. 
14. Schreiber MA, Neveleff DJ (2011) Achieving Hemostais With Topical Hemostats: Making Clinically and Economically Appropriate Decisions in the Surgical and Trauma Settings. AORN 94(5): S1-S20.

15. William H Parker, Willis H Wagner (2016) Management of hemorrhage in gynecologic surgery.

16. Wright D, Ananth C, Lewin S, Burke W, Sidding Z, et al. (2014) Patterns of use of hemostatic agents in patients undergoing major surgery. J Surg Res 86(1): 458-466.

17. http://www.floseal.com/us/pdf/FLOSEAL_Needle-Free_10mL_IFU. pdf

18. Baxter Healthcare: Floseal $®$ hemostatic matrix, instructions for use.

Your next submission with Juniper Publishers will reach you the below assets

- Quality Editorial service

- Swift Peer Review

- Reprints availability

- E-prints Service

- Manuscript Podcast for convenient understanding

- Global attainment for your research

- Manuscript accessibility in different formats

(Pdf, E-pub, Full Text, Audio)

- Unceasing customer service

Track the below URL for one-step submission https://juniperpublishers.com/online-submission.php 